\title{
Static and Dynamic Analysis of Radial Engine Master Rod using ANSYS
}

\author{
Sunil Kumar H E ${ }^{[1]}$, Dr. Mohammed Imran ${ }^{[2]}$, Sagar S R ${ }^{[3]}$ \\ ${ }^{\text {[1] }}$ (PG Scholar, Department of Mechanical Engineering, Ghousia College of Engineering, Ramanagaram, India.) \\ [2] (Assistant Professor, Department of Mechanical Engineering, Ghousia College of Engineering, Ramanagaram , India.) \\ ${ }^{\text {[3] }}$ (Lecturer, Department of Mechanical Engineering, Amruta Institute of Engineering \&Management Sciences - Polythenic, \\ Bidadi (Bangalore), India.)
}

\begin{abstract}
Radial engine is a reciprocating type internal engine configuration, in which the piston moves upward \& downward direction outward from a central crankshaft, radial engine commonly used for aircrafts before they started using turbine engines. In radial engine the pistons are connected for the crankshaft of master and slave (articulating) rod assembly. The model is designed in CATIA V5 R20 and translated to ANSYS $R$ 14.5. The model is simplified in ANSYS by using the preprocessor. Harmonic analysis is carried out to find the various plots of frequency and amplitude for aluminum alloy \& structural steel. Results are obtained, the stresses developed in master rod under static loading and different loading conditions of tension at the crank end $\&$ piston end of master rod. Master rod is modeled by FEM type of design approach to improve the fatigue life of the master rod that is used in Radial engine.
\end{abstract}

Keywords - Aluminum Alloy, ANSYS R 14.5, CATIA V5 R20, FEM, Master Rod, Structural Steel.

\section{INTRODUCTION}

Radial Engine is an interconnecting motor design with the cylinders rising from a central crankshaft as well as from a wheel in the up and down direction. Since the use of turbine engines radial engines were typically used for a number of aircraft. In a radial motor the cylinders are connected with a master rod. One piston is connected to a master rod in which the crankshaft can be mounted directly. The other pistons are fixed to the rings around the end of the master chain. The reciprocal load described on the piston after the spread and even compressed by all rotations, the master stroke undergoes tremendous stress. The load raises to the $3^{\text {rd }}$ power and the engine speed decreases. The failure of a connecting rod that is usually referred to as a "rod throw," is one of the most common reasons for the catastrophic failure of the engine in aero planes which frequently throws the damaged rod across a piston side and even makes the motor irreparably tired of the rod lubrication of failure of a bearing due to a body fatigue. have been published according to stress deformation. All the integrated factors were based to determine the effects and the variance of the static and dynamic stresses of the master rod used in the radial engine by combination impact research on static and dynamic analysis. When the modal analysis decides how the variance in the configuration from the analytics category is performable, the overall speeds, stresses, deviations from various loads, adjust the rotary speed and the speed imported for the master roll are calculated for aluminum alloy \& structural steel material.

\section{LITERATURE SURVEY}

R. Ravi, et.al [1] Paper offers with the study of exploring the load and price reduction but we've got taken the forged steel as the comparison for the material which is better and how to deal with substances in connecting rod. The paper has undergone detailed evaluation of joining pole through dynamic examination of linking bar considered. In the analysis of 1st part, it offers with the observe of static load analysis and materials which is chosen after which taken into account and by using maintaining the production as taken into account. Then in this paper it deals with layout of connecting rod through "CATIA" than the connecting rod is imported to ANSYS work-bench and analysis performed on this paper. Results are acquired by comparing experimental results.

Garima Chaudhary et.al [2] Radial motor displays have long been used in aviation where the radial motor uses very less energy compared to and inadequate output in contrast with other motors. Then utter engine output was transformed in the present turbine engines. They substitute the motor and its output with this paper. A 5-cylinder MOKI-S is tested and checked through the FEA project. The engine's construction is carried out using CATIAV5 and ANSYS obtains a safety factor.

Srikanth Kumar et.al [3] This illustrates the function and use of the radial engine with respect to the master rod, while the piston is mounted with a master rod with an instant crankshaft connection. The remaining pistons are connected to the bottom of the master round by their connecting rods. 4-stroke radials have an unusual number of cylinder rows per row, so that the order of the fire piston can be preserved in a consistent way, so as to promote activity as the different documents the layout is built in PRO-E, the study in ANSYS 13.0 is done.

\section{METHODOLOGY}

The sequence of methodology is listed below:

- Problem formulation and identification through literature survey from various ASME journal, Wikipedia and websites collected towards the present research topic.

- Understanding the working principle of the master rod used in radial engine and reasons for its failure. 
- $\quad$ Modelling of master rod of different geometry in CATIA V5 R20.

- Static structural analysis in ANSYS 14.5 workbench carried out to determine structural strength of the master rod.

- Fatigue analysis of master rod of radial engine in ANSYS 14.5 under different boundary conditions carried out to determine the failure life of master rod.

- Selection of materials for the master rod.

- Applying the material property for the master rod.

- Comparing the materials and showing that which material is best for the master rod.

- Comparisons and validations of the results and improve the fatigue life.

\section{DESIGN OF THE MASTER ROD}

- Span of the connecting rod.

- Radius of the hole and diameters of crank end and piston end.

- Diameter 4-5 dimensions should be noted.

- Length of the rod should be noted and length between crank end and piston end should be noted.

- Finally, all the steps should be followed.

- All dimensions are importing in CATIA V5 R20.

- Design should be made according to the dimensions of the assumption made in the given engine.

Table 1: Parameters of master rod

\begin{tabular}{|l|c|}
\hline \multicolumn{2}{|c|}{ Parameters of the Master Rod } \\
\hline Thickness of the master rod & $5 \mathrm{~mm}$ \\
\hline Width of the section $(\mathrm{B}=4 \mathrm{t})$ & $20 \mathrm{~mm}$ \\
\hline Height of section $(\mathrm{H}=5 \mathrm{t})$ & $25 \mathrm{~mm}$ \\
\hline Height of the big end & $28 \mathrm{~mm}$ \\
\hline Height of the small end & $23 \mathrm{~mm}$ \\
\hline Inner diameter of small end & $24 \mathrm{~mm}$ \\
\hline Outer diameter of small end & $35 \mathrm{~mm}$ \\
\hline Inner diameter of big end & $52 \mathrm{~mm}$ \\
\hline Outer diameter of big end & $69 \mathrm{~mm}$ \\
\hline
\end{tabular}

Table 2: Properties of SS A36 and Al Alloy 6061

\begin{tabular}{|l|c|c|}
\hline \multicolumn{3}{|c|}{ Mechanical Properties } \\
\hline \multicolumn{1}{|c|}{ Properties } & Steel & Al. Alloy \\
\hline Density & $7850 \mathrm{~kg} / \mathrm{m}^{3}$ & $2770 \mathrm{~kg} / \mathrm{m}^{3}$ \\
\hline $\begin{array}{l}\text { Co-efficient of thermal } \\
\text { expansion }\end{array}$ & $1.2 \mathrm{e}-5 / \mathrm{c}$ & $2.3 \mathrm{e}-5 / \mathrm{c}$ \\
\hline Young's modulus (E) & $2 \mathrm{e} 5 \mathrm{Mpa}$ & $2 \mathrm{e} 5 \mathrm{Mpa}$ \\
\hline Poisson's ratio & 0.3 & 0.33 \\
\hline Bulk modulus & $1.66 \mathrm{e} 11 \mathrm{pa}$ & $6.9 \mathrm{e} 11 \mathrm{pa}$ \\
\hline Shear modulus & $7.692 \mathrm{e} 11 \mathrm{pa}$ & $2.669 \mathrm{e} 10 \mathrm{pa}$ \\
\hline Tensile yield strength & $250 \mathrm{Mpa}$ & $280 \mathrm{Mpa}$ \\
\hline Compressive yield strength & $250 \mathrm{Mpa}$ & $280 \mathrm{Mpa}$ \\
\hline Tensile ultimate strength & $460 \mathrm{Mpa}$ & $310 \mathrm{Mpa}$ \\
\hline No. of cycle to failure & $1 \times 106$ & $1 \times 108$ \\
\hline
\end{tabular}

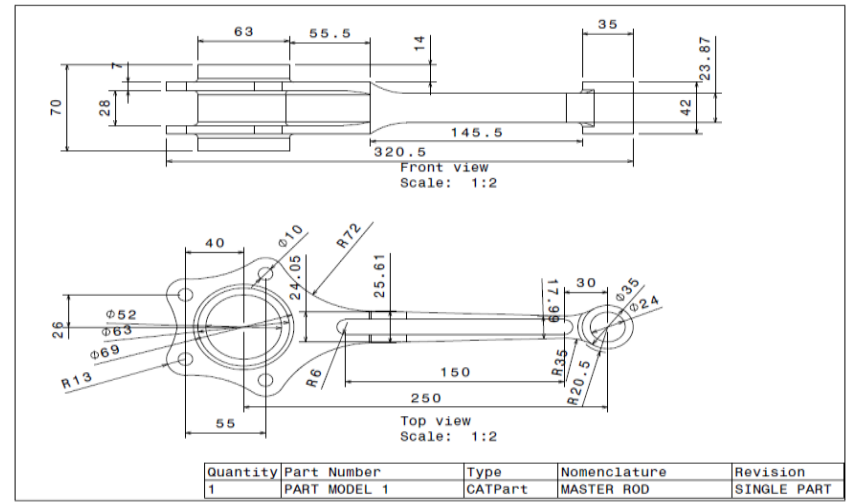

Fig 1: Drafting part of the Master rod

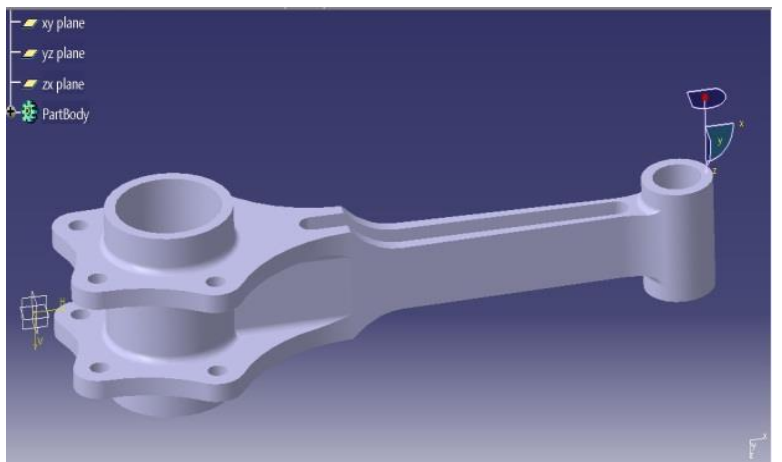

Fig 2: Master rod is developed in CATIA V5 R20

Table 3: Boundary conditions and load applied [2]

\begin{tabular}{|l|l|}
\hline \multicolumn{2}{|c|}{ Boundary conditions } \\
\hline Standard earth gravity & $9806.6 \mathrm{~mm} / \mathrm{s}$ \\
\hline Fixed support & - \\
\hline Rotational velocity & Up to $6000 \mathrm{rpm}$ \\
\hline Force 2 & $-6764 \mathrm{~N}$ \\
\hline Force & 6764 \\
\hline
\end{tabular}

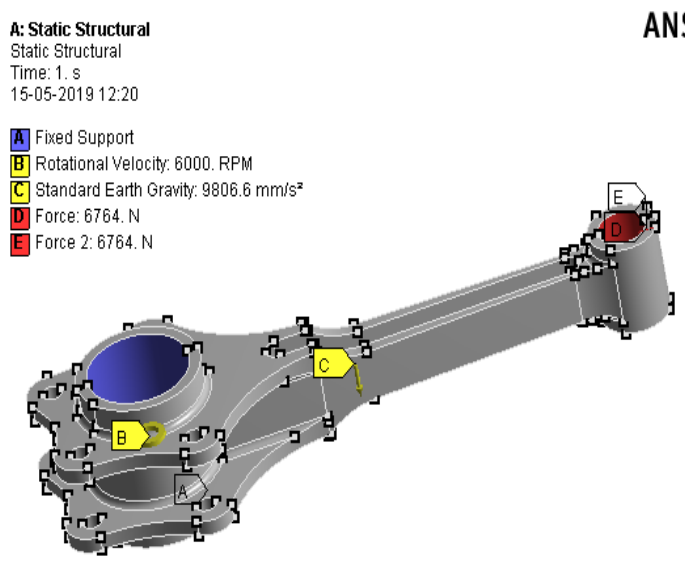

Fig 3: Boundary conditions given for the model 


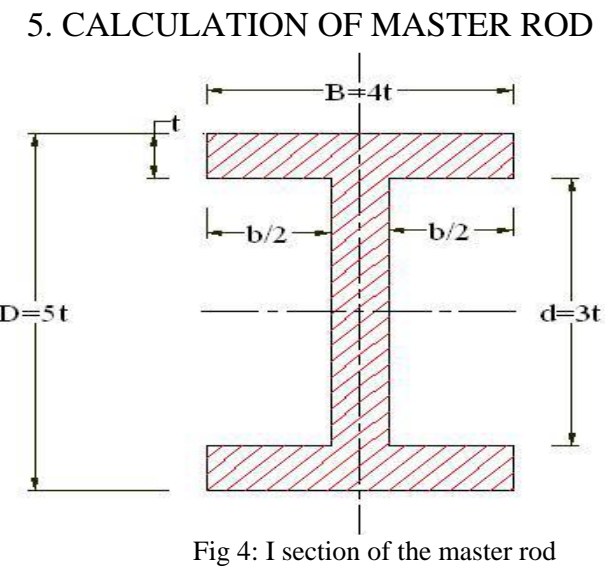

Thickness of the flange $(t)=5 \mathrm{~mm}$.

Width of the section $B=4(t)=20 \mathrm{~mm}$.

Height of the section $H=5(t)=25 \mathrm{~mm}$.

Area of the section $A=11 t^{2}=275 \mathrm{~mm}$

$$
=157.1 \mathrm{rad} / \mathrm{sec}
$$

Inertia force of reciprocating parts

$$
\begin{aligned}
& F=\frac{1000 \mathrm{Wr} V^{2}}{g r} \operatorname{Cos} \theta \pm \frac{\operatorname{Cos} 2 \theta}{n^{1}} \\
& \mathrm{w}=\mathrm{mg}=\text { weight } \text { of reciprocating parts } . \\
& =2 * 9.81 \\
& =19.62 \mathrm{~N}
\end{aligned}
$$

$\mathrm{r}=$ crank radius $=16 \mathrm{~mm}$.

$\theta=$ crank angle from dead centre.

$$
=0
$$

$\mathrm{g}=9.81 \mathrm{~m} / \mathrm{s}^{2}=$ acceleration due to gravity .

$\mathrm{v}=\mathrm{rw}=9.81 \mathrm{~m} / \mathrm{s}$

About the- $I-$ cross section Moment of inertia about $x-x$ is given $b y=15036.8 \mathrm{~N}$

$I x-x=1 / 12\left(B D^{3}-b d^{3}\right)=1 / 12\left\{4 t(5 t)^{3}-3 t(3 t)^{3}\right\}=34.91 t^{2 * 2}$

$$
\begin{aligned}
& =1 / 12\left\{4 \mathrm{t}(5 \mathrm{t})^{3}-3 \mathrm{t}(3 \mathrm{t})^{3}\right\} \\
& =1 / 12\left\{4 * 5\left(5^{*} 5\right)^{3}-3 * 5\left(3^{*} 5\right)^{3}\right\} \\
& =21818.75 \mathrm{~mm}^{4}
\end{aligned}
$$

4.6.2 Total force of connecting rod[2]

$\mathrm{F}_{\mathrm{C}}=\mathrm{F}_{\mathrm{P}}-\mathrm{F}$

$\mathrm{F}_{\mathrm{P}}=$ Force of piston $=21800 \mathrm{~N}[1]$

$\mathrm{Fc}=21800-15036.8$

About the- I - cross section Moment of inertia about $\mathrm{y}-\mathrm{y}$ is given by $\mathrm{F}_{\mathrm{Fc}}=6764 \mathrm{~N}$

I $y-y=1 / 12\left(b d^{3}-B D^{3}\right)=1 / 12\left\{2 t(4 t)^{3}+3 t(t)^{3}\right\}=10.91 t^{2 * 2}$

$$
\begin{aligned}
& =1 / 12\left\{2 \mathrm{t}(4 \mathrm{t})^{3}+3 \mathrm{t}(\mathrm{t})^{3}\right\} \\
& =1 / 12\left\{2 * 5(4 * 5)^{3}+3 * 5(5)^{3}\right\} \\
& =6818.75 \mathrm{~mm}^{4}
\end{aligned}
$$

There fore, Ratio of I x-x and I y-y = I x-x/ I y-y

$$
\begin{aligned}
& =34.91 \mathrm{t}^{2 * 2} / 10.91 \mathrm{t}^{2 * 2} . \\
& =3.19
\end{aligned}
$$

Radius of gyration $\mathrm{Kxx}(\mathrm{K})$ is given by,

$\mathrm{K}=\sqrt{ }(\mathrm{I} / \mathrm{A})=\sqrt{ }\left(34.19 \mathrm{t}^{2 * 2} / 11 \mathrm{t}^{2}\right)=1.78 \mathrm{t}=8.9$.

We know that,

Stroke length $=\mathrm{L}=32 \mathrm{~mm}$.

Therefore, crank radius $\mathrm{r}=\mathrm{L} / 2=32 / 2=16 \mathrm{~mm}$.

$\mathrm{n}^{1}=\mathrm{L} / \mathrm{R}=$ length of master rod/crank radius.

$$
\begin{aligned}
& =250 / 62.5 \\
& =4
\end{aligned}
$$

$\mathrm{W}=$ angular speed

$$
\frac{2 \pi N}{60}=\frac{2 \pi 1500}{60}
$$

\section{RESULTS AND DISCUSSION} Structural Steel

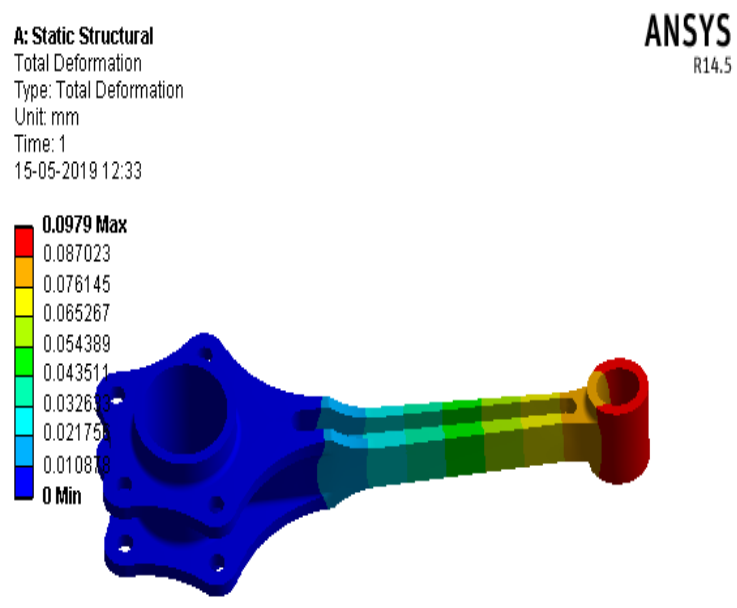

Fig 5: Deformation in the rod for Steel

The total deformation for Structural Steel, maximum deformation of $0.09 \mathrm{~mm}$ and minimum deformation of $0 \mathrm{~mm}$. 


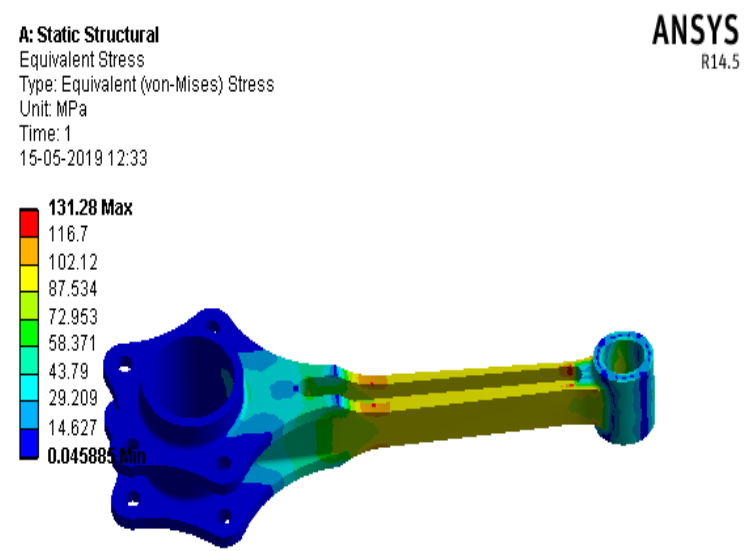

Fig 6: Stress distribution for Steel

Maximum stress of $131.28 \mathrm{Mpa}$ which is shown in red colour region and minimum stress of $0.04 \mathrm{Mpa}$ which is shown in blue colour region. Yield strength of steel material is $250 \mathrm{Mpa}$, working stress is $131.28 \mathrm{Mpa}$ nearest or time fewer than the harvest asset of the substantial hence rotational velocity of $6000 \mathrm{rpm}$ to radial engine connecting rod is applied by considering the factor of safety within the range of 1.5 to 2 .

\section{Aluminum Alloy}

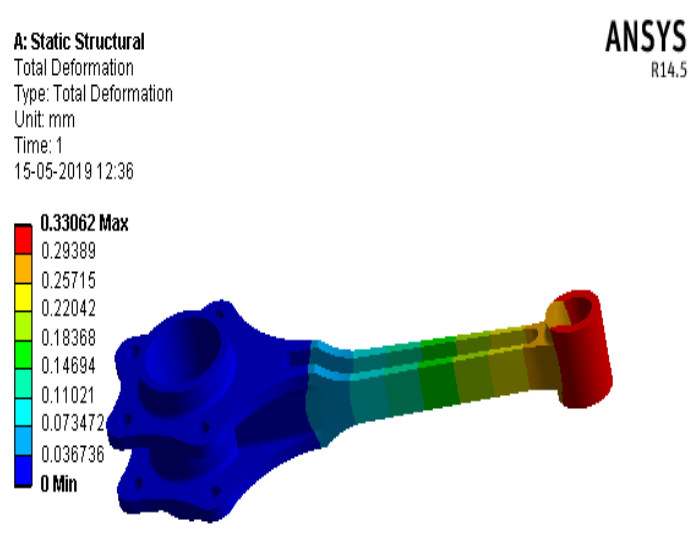

Fig 6: Deformation in the rod for Al Alloy

The total deformation for Aluminum Alloy, maximum deformation of $0.33 \mathrm{~mm}$ and minimum deformation of $0 \mathrm{~mm}$.

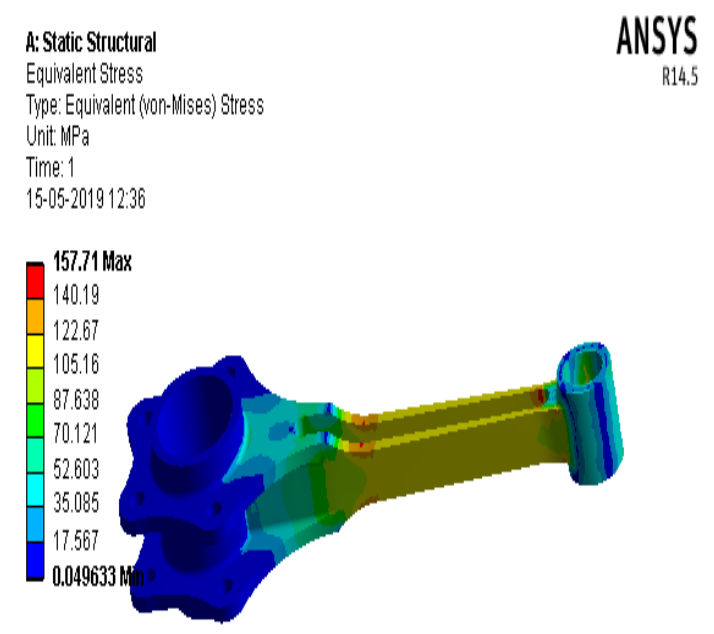

Fig 8: Stress distribution for Al Alloy

Maximum stress of $157.71 \mathrm{Mpa}$ shown in red colour region and minimum stress of $0.04 \mathrm{Mpa}$ shown in blue colour region. Yield strength of steel material is $380 \mathrm{Mpa}$, working stress is $157.71 \mathrm{Mpa}$ is smaller than the harvest forte of the material hence we can give rotational velocity of $11000 \mathrm{rpm}$ to radial engine connecting rod, considering the factor of safety within the range of 2.4 to 2.8 .

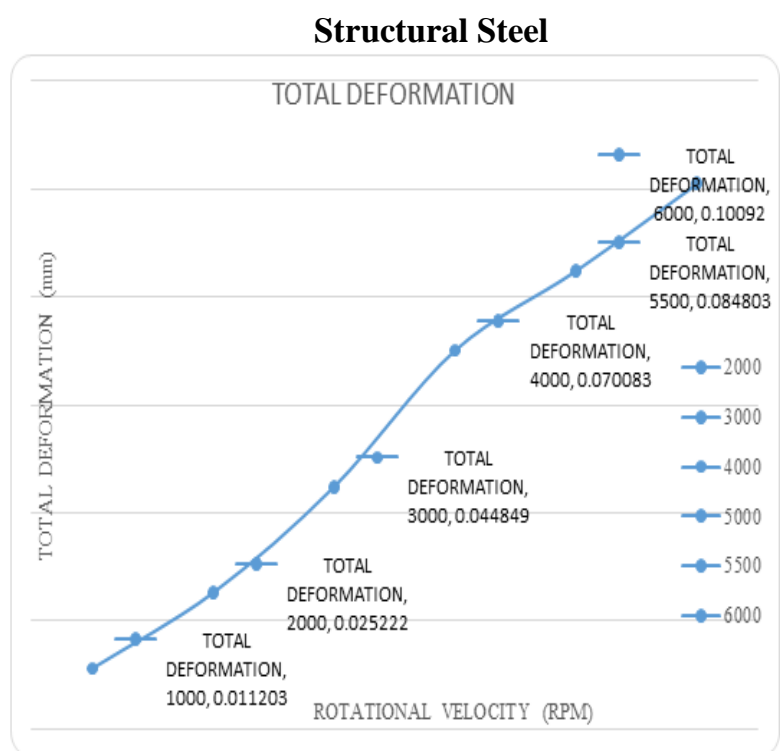

Graph 1: Deformation v/s Rotational velocity 


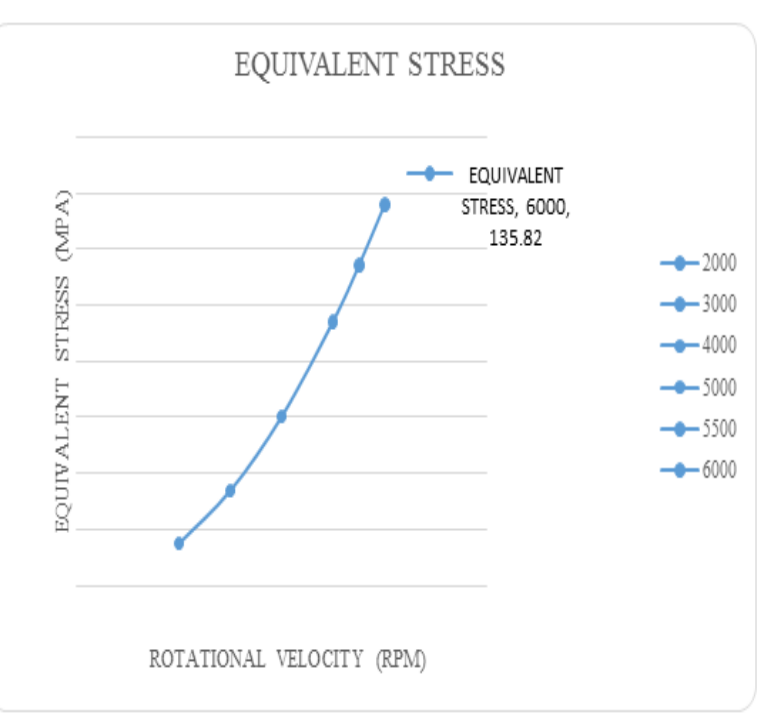

Graph 2: Stress v/s Rotational velocity

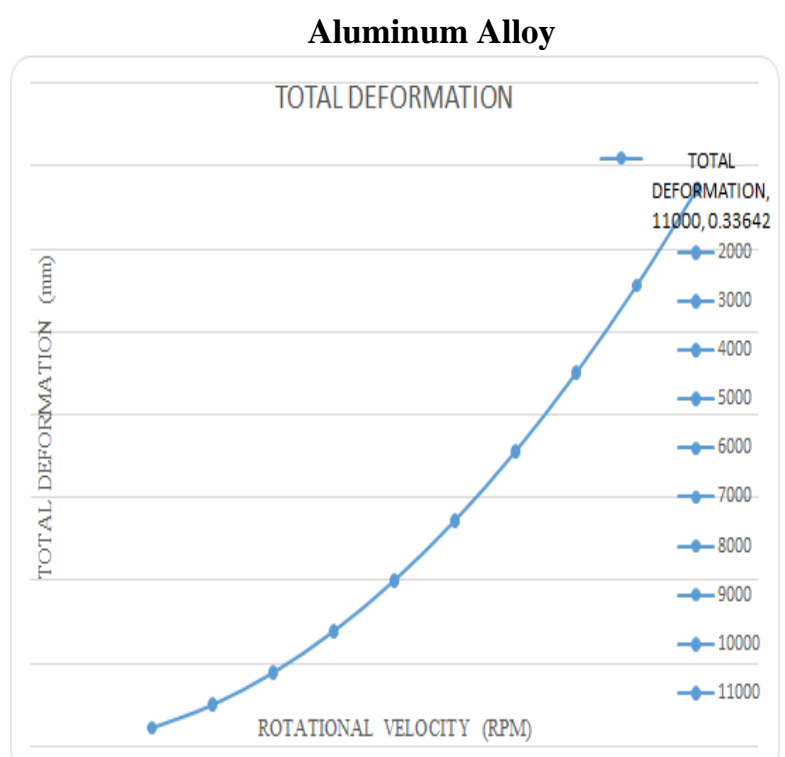

Graph 3: Deformation v/s Rotational velocity

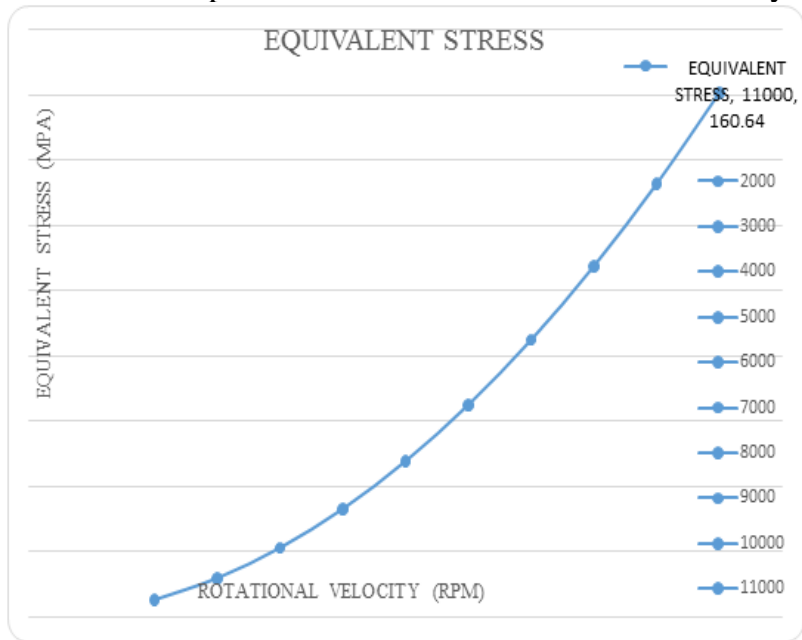

Graph 4: Stress v/s Rotational velocity

\section{Comparison of fatigue life for $\mathrm{Al}$ and Steel}

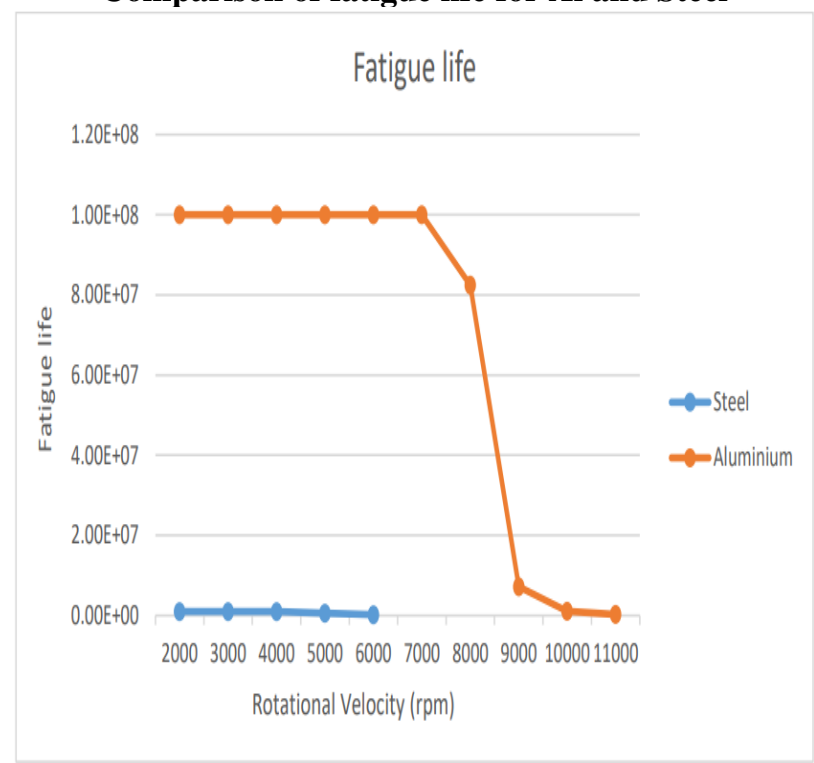

Graph 5: Comparison of fatigue life for Al \& Steel

\section{Comparison of FOS for Al and Steel}

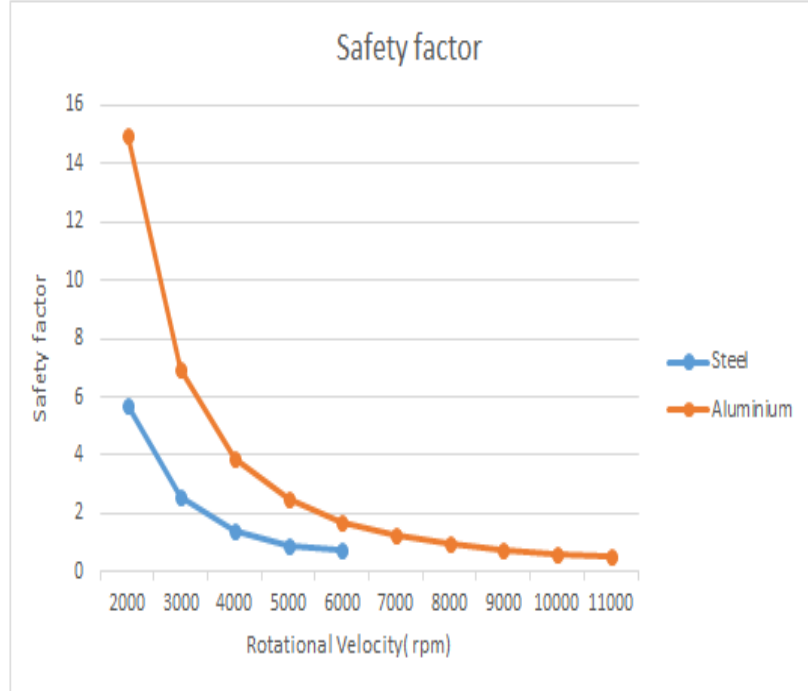

Graph 6: Comparison of FOS for Al \& Steel

The variation of fatigue life for rotational velocity for $\mathrm{Al}$ and steel represented in graph 5 . It is observed that fatigue life of $\mathrm{Al}$ is more when compared to steel material. The variation of factor of safety for rotational velocity for $\mathrm{Al}$ and steel represented in graph 6. It is observed that factor of safety for $\mathrm{Al}$ is more when compared to steel material. By this positive result, it is observed that $\mathrm{Al}$ material have higher fatigue strength and structural strength than.

\section{CONCLUSIONS}

The static analysis maximum equivalent stress distribution in radial engine connecting rod is $131.28 \mathrm{Mpa}$. The maximum stress occurred at crank end and yield strength of steel material is $250 \mathrm{Mpa}$, working stress is $131.28 \mathrm{Mpa}$, which is much less than the yield strength of the material hence rotational velocity of 6000rpm to radial engine connecting rod is applied by considering the factor of 
safety within the range of 1.5 to 2 , once increased in rotational velocity above 6000rpm for steel, connecting rod will leads to fail, hence maximum rotational velocity should be within 6000rpm for steel material.

The static analysis the equivalent stress distribution in radial engine connecting rod is $157.71 \mathrm{Mpa}$. The maximum stress occurred at crank end and hence it need to take care about the thickness of the crank end, yield strength of aluminum alloy is $280 \mathrm{Mpa}$, working stress is $157.71 \mathrm{Mpa}$ is lesser than the yield strength of the material hence providing rotational velocity of $11000 \mathrm{rpm}$ to radial engine connecting rod, considering the factor of safety within the range of 2.4 to 2.8 , once it increased rotational velocity above $11000 \mathrm{rpm}$ for aluminum alloy, connecting rod will leads to fail, hence maximum rotational velocity should be within $11000 \mathrm{rpm}$ for aluminum material.

The total deformation distribution in radial engine connecting rod is $0.09 \mathrm{~mm}$. Minimum deformation is $0 \mathrm{~mm}$, because at the fixed end geometry does not allow to deform similarly for aluminum maximum deformation of $0.33 \mathrm{~mm}$ and minimum deformation of $0 \mathrm{~mm}$. Fatigue life $1.19 \times 105$ cycles was observed in the geometry, it clearly shown in red colour region at crank end and maximum fatigue life 1x106 and similarly for aluminium Fatigue life 2.94x105 cycles and maximum fatigue life $1 \times 108$. Aluminium Alloy has $59.52 \%$ more fatigue life and strength than structural steel.

\section{ACKNOWLEDGEMENTS}

I would like to express my profound gratitude to Dr. Mohammed Imran, Assistant Professor in Mechanical Engineering Department, Ghousia College of Engineering, Ramanagaram, for his guidance and useful suggestions, which helped in completing the project work in time.

I express my sincere thanks to beloved Principal Dr.A.R. Anwar Khan, Ghousia College of Engineering, Ramanagaram, for providing me an opportunity to fulfill my desire of reaching my goal and thus helping me to make a bright future.

I express my sincere thanks Sagar S R, Department of Mechanical Engineering, Amruta Institute of Engineering \&Management Sciences - Polythenic, Bidadi (Ramanagaram) for providing me an opportunity to fulfill my desire of reaching my goal and thus helping me to make a bright future.

I would also thank all the Ghousia College of Engineering teaching and non-teaching staff of department of mechanical engineering for their kind support during the course of work. The support provided by the department library is gratefully acknowledged.

\section{REFERENCES}

[1]. Sri kanth kumar and B. Jitendra (IETRJ) International Engineering and Technology Research Journal, Vol. 2(1), 2015, 131-135.

[2]. Finite Element Analysis of Connecting Rod Using Ansys 1nikhil U. Thakare, 2nitin D. Bhusale, 3rahul Shinde, 4mahesh M. Patil 1,3,4b.E., Babasaheb Naik College of Engineering, Pusad, Maharashtra, India, 2research Scholar

[3]. NACA aero 23 profile

[4]. Ansys help menu and from moki engine website

[5]. Dr. Mohammed Imran, Compitational Fluid Flow Dynamic Analysis on I.C Engine using ANSYS, International Journal of Engineering Research and Technology, Vol. 4(6), 2015, 6 